\title{
O processo de reconstrução do Ministério Público na transição política (1974-1985)
}

\author{
The reconstruction process of the Public Prosecutor's Office in the \\ political transition (1974-1985)
}

\section{Débora Alves Maciel Andrei Koerner}

\section{Resumo}

O artigo analisa a dinâmica da reconstrução do Ministério Público (MP), focalizando a mobilização de promotores e de procuradores de justiça, no período de 1974-1985. Argumentamos que as características da transição política brasileira foram decisivas para o processo de mudança da instituição que ganhou status constitucional em 1988. A liberalização do regime militar modificou os vínculos entre juristas, oposição partidária e movimentos pró-democracia. A conexão do movimento institucional com as elites políticas dissidentes e a densa rede de ativismo em torno de novos conflitos sociais permitiu ao Ministério Público experimentar novas estratégias de ação coletiva, ganhar visibilidade política e, assim, tornar-se alternativa viável para o sistema político responder às pressóes sociais para a democratização do judiciário.

\section{Palavras-chave}

Ministério Público; Interesses Difusos; Reforma do Judiciário; Transição Política; Mobilizações Pródemocracia.

\section{Abstract}

The article analyzes reconstruction dynamics of the Public Prosecutor's Office, focusing on the mobilization of prosecutors and prosecuting attorney in the period from 1974 to 1985 . We argue that the characteristics of Brazilian political transition were critical to the changing process of the institution, which gained constitutional status in 1988. Liberalization of the military regime changed the links between lawyers, opposition parties and pro-democracy movements. The connection of the institutional movement with dissident political elites and the dense activism network around new social conflicts allowed the Public Prosecutor's Office to try new strategies of collective action, gain political visibility and thus become a viable alternative to political system to respond to social pressures for judiciary democratization.

\section{Keywords}

Public Prosecutor's Office; Diffuse Interests; Judicial Reform; Political Transition; Pro-Democracy Mobilizations. 


\section{Introdução ${ }^{1}$}

A Assembleia Nacional Constituinte (1986-1987) consistiu não apenas na superação - parcial e negociada - do regime militar, mas em processo decisório aberto a vários grupos de pressão e segmentos sociais. Nesse sentido, representou oportunidade política ímpar para agentes, mobilizados ao longo da transição (19741985), angariarem legitimidade normativa para suas pautas e interesses, permitindo a confluência do discurso do estado de direito, sustentado pela oposição política e os dissidentes liberais do regime, e do da redemocratização, a bandeira comum da densa e diversificada rede de protesto antirregime. Nas mobilizaçóes em torno da construção da nova constituição, a linguagem dos direitos deu sustentação ao conjunto heterogêneo de reivindicações, transformando a ampliação e o fortalecimento das instituiçôes judiciais em parte inseparável da própria democratização política (FALCÃO NETO, 1981).

A Constituinte tornou-se arena pública não apenas para movimentos de cidadãos comuns, mas também para grupos de interesse e associações profissionais. As diversas carreiras jurídicas se engajaram intensamente no processo político, seja como corporaçóes, como grupos de experts ou como agentes sociais comprometidos ideologicamente com a construção da nova ordem democrática (KERCHE, 2010; KOERNER e FREITAS, 2013; ROCHA, 2013).

Um dos resultados mais surpreendentes do processo político foi, como sabemos, o redesenho das instituições judiciais. Estas receberam novas e amplas atribuições, ao mesmo tempo em que princípios e regras garantiram sua autonomia institucional e funcional, permitindo seu insulamento em face de mudanças legais. A nova concepção do Ministério Público (MP) derivou dessas mudanças. De órgão tradicionalmente vinculado ao Executivo como defensor dos interesses da União, tornou-se política e administrativamente independente e legitimado a agir por meio da ação civil pública na proteção e promoção de direitos coletivos de natureza difusa² .

\footnotetext{
${ }^{1} \mathrm{O}$ artigo resulta de projetos de pesquisa financiados pelo Conselho Nacional de Desenvolvimento Tecnológico e Científico (CNPq) que trataram de temas conexos: o da reconstrução do movimento institucional do Ministério Público no período de 1974-1985 (hospedado pelo Núcleo de Apoio à Pesquisa sobre Democratização e Desenvolvimento da Universidade de São Paulo - NADD/USP); o do processo constituinte (realizado no Centro de Estudos de Cultura Contemporânea - CEDEC); e o do pensamento constitucional nos anos noventa (realizado no Grupo de pesquisas sobre Política e Direito/Centro de Estudos Internacionais e de Política Contemporânea da Universidade Estadual de Campinas - GPD/CEIPOC/Unicamp).

2 São exemplos de direitos coletivos de natureza difusa a preservação do meio ambiente natural, histórico e cultural, da integridade do patrimônio público e da probidade administrativa, assim como
} 
$\mathrm{O}$ MP conquistou independência político-institucional equiparando-se às prerrogativas e garantias funcionais do Judiciário ${ }^{3}$. As mudanças traduziram parte da pauta do movimento associativo consolidada na Carta de Curitiba ${ }^{4}$ que foi defendida pela Confederação Nacional do Ministério Público (CONAMP) durante a Constituinte.

O problema analítico que o evento suscita se traduz na seguinte pergunta: qual processo político teria possibilitado que objetivos associativos fossem aceitos como propósitos públicos e convertidos, pelo menos em parte, em normas constitucionais?

Arantes (2002) e Kerche (2010) propuseram explicações para a mudança institucional. A renovação do papel do MP no sistema de justiça é concebida como um dos produtos da "judicialização da política" responsável pela (suposta) oposição entre política partidária e política de direitos na democracia brasileira contemporânea. Para Arantes (2002), o redesenho da instituição teria decorrido de lobbies das lideranças associativas, desde os anos 1970, que já haviam resultado na Lei Orgânica Nacional (1981) a qual uniformizou nacionalmente a carreira, e a Lei da Ação Civil Pública (1985) que legitimou o uso de novos instrumentos jurídicos. A ampliação do poder institucional teria tido caráter estritamente corporativo, e não democrático, pelo fato de a mobilização política de promotores e procuradores de justiça ter sido deflagrada ainda no regime militar antecipando-se à Constituição de 1988. Para Kerche (2010), o lobby não teria sido suficiente para garantir a constitucionalização do projeto do MP, pois além do sucesso da CONAMP ter sido parcial houve a concorrência de outros segmentos como os delegados e a magistratura. $\mathrm{O}$ projeto do MP teria sido bem sucedido "em 'vender' seu projeto" por ser coerente com os tópicos fundamentais do processo político daquele momento: os direitos coletivos e o

as relações de consumo e os interesses de grupos em situação de risco social e/ou de violência (minorias étnicas, sexuais e religiosas, pessoas portadoras de deficiência física, idosos, crianças e adolescentes).

3 Os órgãos superiores de execução tornaram-se responsáveis pelos critérios do plano de carreira (inserção, promoções e remoçóes), pela proposta orçamentária e pelo estabelecimento de metas e prioridades organizacionais. Em termos funcionais, seus membros alcançaram garantias constitucionais quanto: a) à independência no exercício do cargo (autonomia frente aos órgãos superiores nas iniciativas e condução dos casos sob sua responsabilidade); b) à vitaliciedade e inamovibilidade do cargo (a perda ou remoção da função não são decorrentes exclusivamente de decisões administrativas, mas de procedimentos judiciais que permitem ampla defesa do seu portador); c) à irredutibilidade salarial (a redução dos vencimentos da categoria não pode ocorrer sem alteraçóes constitucionais) (MAZZILLI, 1997).

${ }^{4}$ A Carta de Curitiba foi elaborada em encontro nacional do Ministério Público realizado, em 1986, às vésperas da Constituinte. 
papel político do sistema de justiça (KERCHE, 2010, p. 135 e 136). Essa interpretação, contudo, ainda restringe o processo político às preferências ideológicas das elites políticas, no caso, os parlamentares de esquerda que teriam optado pelo modelo independente em virtude de sua nova visão da sociedade e do estado.

Os trabalhos de Arantes (2002) e Kerche (2010) trouxeram contribuições relevantes para a compreensão do caráter agente e corporativo da mobilização coletiva do MP em direção à mudança institucional. Mas essa é, contudo, uma interpretação parcial por não considerar sua conexão com o movimento associativo e com o processo mais amplo da transição política. Focalizando dimensóes macro e micro estruturais da mudança institucional, procuramos demonstrar que oportunidades políticas abertas pela transição contribuíram para impulsionar o movimento do MP para as redes pró-democracia, e renovar alianças e estratégias de ação coletiva para além do lobby. Não se trata de negar a face corporativa da mobilização política de promotores e procuradores de justiça, mas de destacar as condições sociopolíticas sob as quais a pauta institucional foi vinculada ao movimento geral pela democratização e, assim, angariou legitimidade pública como alternativa viável para o sistema político responder às pressões sociais para a democratização do judiciário.

$\mathrm{O}$ artigo está organizado em três seções. A primeira trata das fontes do descontentamento institucional e das primeiras mobilizaçôes ainda no regime militar. A segunda analisa a reforma do judiciário do Governo Geisel e as mudanças nas relações entre as elites jurídicas e o regime. A última seção é dedicada à mobilização do MP em meio ao ciclo de protesto pró-democracia 5 .

\section{Fontes do descontentamento institucional e tensões politicas no regime militar}

A Revolução de 1930 deflagrou o processo de autonomização das instituições judiciais e a profissionalização das carreiras jurídicas. Com o fortalecimento do Estado nacional e a expansão de sua capacidade de direção e regulação da sociedade, as novas atribuições do Judiciário na organização da competição eleitoral e as garantias à oposição política e à contestação social foram combinadas com a ampliação do seu campo de atuação. Esse processo resultou na ampliação de atribuiçôes do Ministério Público como também de outras carreiras jurídicas ${ }^{6}$.

\footnotetext{
5 A análise é baseada em dados sobre o MP de São Paulo e eventos nacionais de mobilização. A pesquisa permite destacar o papel da liderança paulista no processo de nacionalização do movimento institucional, mas sem ignorar a especificidade dos contextos políticos regionais.

${ }^{6}$ O Código de Processo Civil de 1939 uniformizou nacionalmente a obrigatoriedade da intervenção do MP como fiscal da lei na proteção de direitos indisponíveis. A intervenção institucional se
} 
A pauta corporativa do MP carregava uma questão política: a plena estruturação da carreira exigia a blindagem da instituição contra ingerências externas. Ou seja, a consecução de interesses e vantagens profissionais não estava dissociada da autonomia funcional dos seus membros e do poder institucional de decisão. Ambos se combinaram em reivindicaçôes recorrentes na trajetória da instituição: o concurso público de título e provas para o ingresso na carreira, a garantia de inamovibilidade, e a escolha dos procuradores gerais (PGE) dentre os integrantes da carreira para barrar nomeações ligadas à política partidária.

Vantagens profissionais e garantias dos promotores foram perseguidas, desde então, enquanto o tema da independência institucional aparecia em manifestaçôes isoladas e retóricas, de MP estaduais com carreiras mais estruturadas, como em São Paulo, no Rio Grande do Sul e em Minas Gerais (FERRAZ, 1997a e 2000; MAZZILLI, 1996) ${ }^{7}$. A disparidade regional nos padrôes de carreira representava obstáculo para construir mobilizações associativas de abrangência nacional. Havia incerteza nas relações com o sistema político, dada a inexistência de regras constitucionais ou de lei nacional da organização a respeito ${ }^{8}$. Mas tal cenário também abria a porta para mobilizações por prerrogativas e para definição e ampliação do papel institucional.

O regime militar acirrou a tensão entre carreira e vinculação política aos governantes. A ordem política militar-autoritária caracterizou-se pela duplicidade normativa que consistia na coexistência de normas legais derivadas de fontes de legitimidade contraditórias com a finalidade de institucionalizar as estruturas de poder político (KLEIN e FIGUEIREDO, 1978; SALLUM, 1996). Normas constitucionais mantiveram regras do regime representativo, enquanto Atos

concentrava, sobretudo, em conflitos e direitos individuais, e cabia ao MP representar os interesses do Executivo em juízo (MACEDO JR., 1997). Na área penal, as atribuiçóes foram consolidadas com o Código de Processo Penal da década de 1940 (SALLES, 1999).

7 O MP paulista se destacava pelos avanços corporativos e institucionais, desde a Constituição Estadual de 1947, representados pela equiparação de vencimentos com a magistratura; pela vedação do exercício da advocacia; e pela previsão constitucional do Conselho Superior, órgão disciplinar interno, importante por mitigar a discricionariedade do poder político nos processos de promoção ou remoção. Com a chamada "Lei Áurea do Ministério Público", de 1954, o PGE passou a ser obrigatoriamente da carreira e foi introduzido o sistema de lista tríplice elaborada pelo Colégio de Procuradores dentre para a escolha do PGE (MACEDO Jr., 1997; SALLES, 1999).

${ }^{8} \mathrm{Na}$ Constituição de 1934, o MP estava inserido em capítulo relativo aos Órgãos de Cooperação nas Atividades Governamentais; na Constituição de 1946, em capítulo próprio; e na de 1967, vinculado ao Poder Judiciário. 
Institucionais impostos por decreto do Executivo franqueavam à Presidência da República a capacidade de mudar as regras (ALVES, 1985; SKIDMORE, 1988).

A Constituição de 1967 foi uma expressão da tentativa de institucionalização do regime. Esta reforçou as atribuiçôes do Poder Executivo e sua influência sobre o Legislativo e o Judiciário, criando, dessa forma, uma hierarquia constitucional centralizadora. O MP, na dupla condição de fiscal da lei e representante judicial do Executivo, tornou-se instituição estratégica na defesa dos interesses da União. As atribuições, especialmente do chefe do Ministério Público Federal - o ProcuradorGeral (PGR) -, foram significativamente ampliadas visando a fiscalizaçáo da obediência às regras jurídicas e conveniências do regime. A Constituição previu, entre outras, a representação do PGR perante o STF contra abusos no gozo de direitos individuais, e o poder para requerer preliminarmente a suspensão do mandato parlamentar nos processos relativos a crimes contra a Segurança Nacional.

Com o recrudescimento do autoritarismo a partir da decretação do Ato Institucional no 5 (AI-5), o MP é colocado no capítulo do Poder Executivo por meio da Emenda Constitucional no 1 de 1969. Houve notável concentração das atribuições do PGR que se tornou cargo de confiança do Presidente da República, com nomeação sem mais participação do Senado Federal (MAZZILLI, 1996). O controle político do MP permitia ao Executivo selecionar integrantes confiáveis para compor a cúpula e cassar promotores de justiça quando fosse conveniente. Os expurgos já haviam se iniciado com a "Operação Limpeza", em 1964, que se destinava à investigação do envolvimento de funcionários civis e militares em atividades subversivas. A Operação foi levada a cabo pelas comissões especiais de inquérito criadas em todos os níveis de governo e da burocracia estatal (ALVES, 1985).

A vulnerabilidade da instituição precipitou as primeiras reações que, no caso de Sáo Paulo, foram lideradas por uma jovem geração de promotores públicos, ingressantes na carreira em fins dos anos $50^{\circ}$. Durante a tramitação do projeto da Constituição de 1967 no Congresso Nacional, lideranças paulistas pressionaram para manter as garantias e prerrogativas constitucionais no Estado. A Emenda Constitucional de 1969 sinalizava claramente para a base da instituição que a centralização de atribuições na cúpula trazia o risco de uniformização conforme o

\footnotetext{
${ }^{9}$ Ronaldo Porto Macedo, Carlos Siqueira Netto, João Lopes Guimarães, Antonio Celso Di Munno Correa, Hermes Pinotti e Ewelson Soares Pinto. Os três primeiros ocuparam a presidência da Associação Paulista do Ministério Público (APMP) entre 1971 e 1976 (FERRAZ, 1997).
} 
modelo do Ministério Público da União $^{10}$. A concentração do poder político impulsionou a nacionalização do movimento associativo com a criação, em 1971, da Confederação das Associações Estaduais do Ministério Público, futura CONAMP. A nova estrutura de mobilização fomentou o surgimento de novas associações pelo país. O associativismo se converteu, ao longo da década de 1970, de grêmio originalmente dedicado à prestação de serviços, lazer e congraçamento, em veículos de mobilização política (ENGELMAN, 2006), tendo à frente a CONAMP na difusão do modelo institucional dos ministérios públicos mais autônomos, como o de São Paulo ${ }^{11}$.

\section{A reforma do Judiciário e a mobilização de juristas ${ }^{12}$}

A transição política brasileira se caracterizou pelo projeto de fundamentação e de organização jurídico-constitucional do regime, pela incerteza do processo político nas interações entre governo e oposição, e pelas pressões de uma oposição não partidária engajada nas mobilizaçôes de massa pró-democracia a partir de 1977.

O processo da reforma do Judiciário (1974-1977) e os seus resultados constituíram dimensão importante do contexto da liberalização política. A relevância resulta não só do significado do seu desfecho para a transição política - o "Pacote de Abril” imposto ao Congresso Nacional em 1977 -, mas também da inflexão que gerou nas relaçóes entre as elites jurídicas e o governo militar.

Embora não haja certeza sobre a estratégia global do governo Geisel ao investir na chamada distensão, ou normalização institucional, sabe-se que ele promoveu uma série de mudanças políticas para neutralizar o aparato repressivo e construir compromissos com a oposiçáo moderada, de modo a conduzir a uma situação de legalidade e de participação política limitada. A oposição reivindicava a volta ao estado de direito, com a revogação do AI-5, a anistia e as eleições diretas, enquanto o governo enfatizava a necessidade de salvaguardas institucionais que substituíssem os atos institucionais e a repressão sistemática. Essas salvaguardas seriam construídas por meio da constitucionalização de eleiçôes indiretas, de limites aos

\footnotetext{
10 "A maioria dos Ministérios Públicos dos Estados não havia chegado ao desenvolvimento institucional de São Paulo e isso, para nós, constituía uma inconveniência e um perigo, porque no plano federal a idéia (sic) de Ministério Público era o modelo da União” (FREITAS, 2003, p. 5).

11 “[...] o ideal da CONAMP, ainda no regime militar, era conquistar os outros estados para o modelo paulista, para que o modelo da União não prevalecesse [...] Assim uma das nossas primeiras reivindicaçôes era separar as funçóes para que não se confundisse a Advocacia da União com o Ministério Público" (sic) (FREITAS, 2003, p. 5).

${ }^{12}$ A seção sintetiza resultados de pesquisa apresentados em Koerner (2012).
} 
poderes do Congresso em matérias de defesa do Estado e de segurança, ao mesmo tempo em que a contestação política passaria a ser controlada por meios legais.

O investimento do Presidente Geisel, desde o início do governo, na reforma nacional do Poder Judiciário visava ampliar as atribuições das instituições judiciais que seriam centralizadas por mecanismos de controle disciplinar interno. $\mathrm{O}$ tema foi introduzido na agenda política com discurso modernizador: aumentar o acesso à justiça e a eficiência do Judiciário, unificar a organização e fortalecer os controles sobre os procedimentos e pessoal. A reforma tinha quatro propósitos imediatos: reforçar o papel do Supremo Tribunal Federal (STF) para garantir os limites e o equilíbrio da Constituição positiva em face de desafios ao governo federal, provenientes do Congresso e de outros entes estatais; proporcionar instrumentos mais efetivos para a disciplina dos juízes e o controle de decisões desfavoráveis; fortalecer o apoio dos magistrados ao regime por meio do reconhecimento profissional e da promoção de melhores condições de trabalho e remuneração; e ampliar o apoio social difuso ao regime, com a adequação do Judiciário ao "estágio de desenvolvimento do país" proporcionando uma "justiça rápida e barata" para a população.

A estratégia para a construção da reforma foi a de mobilizar as cúpulas do Judiciário, e dos órgãos de representação das profissões jurídicas, para o levantamento de informaçôes e sugestôes a serem enviadas a uma comissão de reforma no STF. Caberia ao STF realizar o diagnóstico e estruturar o anteprojeto. A pretensão era apresentar ao Congresso um anteprojeto já consolidado, a ser aprovado sem maior debate ou oposição, com a alegação de que se tratava de matéria técnica já apreciada pelos especialistas. Assim, o governo controlava a discussão sobre as reformas, sem aceitar as demandas da oposição, ao mesmo tempo em que promovia o esvaziamento do Congresso, ao suprimir os debates parlamentares e fortalecer os poderes de controle do STF.

Embora as expectativas do governo e do STF fossem a de um andamento rápido, a reforma permaneceu na agenda política por três anos. O projeto encontrava resistências entre juristas, oposição política e outros setores. Além disso, depois das eleiçôes de 1974 o governo havia perdido a maioria qualificada na Câmara, necessária para aprovar propostas de emenda constitucional.

A proposta de Emenda Constitucional para a reforma do Poder Judiciário foi enviada pelo governo Geisel ao Congresso Nacional, em novembro de 1976, onde se 
formou uma comissão mista para exame da matéria e o recebimento de emendas ${ }^{13}$. $\mathrm{O}$ senador Acioly Filho da Aliança Renovadora Nacional (ARENA), nomeado relator, fez amplo levantamento de sugestôes, em viagens pelos estados e em reunióes com juristas, mas o seu substitutivo foi rejeitado pelo governo. Ao mesmo tempo, se configurava o impasse entre governo e Movimento Democrático Brasileiro (MDB) em torno das reformas políticas. Levado a votação, o projeto original do governo para a reforma do Judiciário não alcançou a maioria de votos necessária para sua aprovação. Em resposta, o governo usou medida excepcional para fechar o Congresso e implementar as alteraçôes constitucionais. O "Pacote de Abril" decretou as Emendas Constitucionais no 7 e 8 , e normas complementares que reformaram o Judiciário, estabeleceram novas regras para as eleições indiretas para Presidente e governadores, e modificaram regras do processo legislativo e da representação política no Congresso.

Ao usar a reforma do Judiciário como pretexto, o governo foi capaz de impor as mudanças constitucionais com as quais manteve o processo político sob controle. Todavia, a dinâmica e o desfecho da reforma resultaram em inflexão nas relaçóes entre elites jurídicas e governo, que passaram do distanciamento à oposição aberta ao regime.

A reforma centralizadora, com a concentração no STF de atribuições constitucionais e controles disciplinares sobre os juízes ${ }^{14}$, antagonizava com interesses de juízes, juristas e elites políticas estaduais, e, até mesmo os presidentes dos tribunais de justiça dos grandes estados foram irredutíveis aos propósitos do governo. Os modelos dominantes entre os juristas eram favoráveis ao retorno da descentralização e da autonomia das instituições judiciais, que vigoraram até 1964. Se a afirmação desses interesses não se apresentava inicialmente como antagonismo, mas como dissonâncias e discordâncias pontuais com o governo, a reforma estimulou desde cedo críticas e resistências por envolver interesses das elites políticas estaduais e dos juízes. Ganhavam visibilidade e apoios os opositores do regime e dissidentes liberais que postulavam a volta ao estado de direito como condição essencial para realizar qualquer reforma do Judiciário digna desse nome.

\footnotetext{
${ }^{13}$ A PEC n 29-76 acolhia demandas das carreiras jurídicas sobre formação profissional, remuneração e carreira, mas mantinha todos os pontos polêmicos e criticados pelos juristas e pela oposição. E, evidentemente, não trazia qualquer restauração do estado de direito.

${ }^{14}$ Tais fatores correspondem ao Conselho da Magistratura, a interpretação de lei em tese, a avocatória, a arguição de relevância para o recurso extraordinário, o contencioso administrativo e a extinção dos tribunais de alçada.
} 
A estratégia inicial do Governo Geisel, de construir consenso entre os juristas em torno da reforma, abriu oportunidade política para a mobilização em eventos nacionais, encontros, congressos e seminários. As sugestôes foram elaboradas não só pelos Tribunais de Justiça, mas em conjunto com outras instituiçôes judiciais estaduais. Os documentos traziam pautas institucionais e demandas de garantias que foram tornadas públicas e debatidas pelas diferentes carreiras jurídicas.

A insistência governamental na reforma rejeitada pelos juristas bloqueou sua interlocução com os dirigentes de tribunais e organizações jurídicas ${ }^{15}$. Em resposta, associaçóes de classe passaram apresentar suas propostas diretamente ao Congresso, o que contrariou o propósito governamental de limitar a participação dos juristas à apresentação de sugestôes à comissão de reforma do STF e excluir o Congresso dos debates.

A perspectiva de reformas, aliada à sinalização de distensão, acabou politizando as posiçóes em torno do alcance da reforma. Em 1974, apenas a Ordem dos Advogados do Brasil (OAB), o MDB e dissidentes liberais estabeleciam a volta ao estado de direito como condição preliminar para a reforma do Judiciário. Nos anos seguintes, a defesa do estado de direito ganhou adesóes, que se manifestavam abertamente ou por meio da rejeição a pontos específicos da reforma. A partir de 1975, era nítida a convergência do $\mathrm{MDB}$ e da OAB com outras organizações de juristas que postulavam a volta ao estado de direito como pré-condição para a aprovação da reforma do Judiciário e de outras reformas políticas pelo Congresso.

A reforma do Judiciário acabou por reunir agentes jurídicos dispersos, cujos interesses e valores estavam em dissonância ou afastamento com o regime, aproximando-os da oposição política. O uso político da reforma transformou pontos de atrito entre juristas em relação ao projeto do governo em posicionamentos a favor ou contra o regime. Ao bloquear o debate com os dirigentes de tribunais e entidades jurídicas, o governo propiciou a reorganização do associativismo de juristas e a formulação de pautas para a recomposição do Poder Judiciário.

\footnotetext{
${ }^{15}$ Segundo Paulo Brossard (1977), o STF não se manifestou sobre o projeto do governo, mas houve manifestações de rejeição ao projeto pelo Tribunal Federal de Recursos (TFR), por ministros do Tribunal Superior do Trabalho (TST), por Tribunais de Justiça e Tribunais Regionais do Trabalho, pelo Conselho Federal da OAB, pelas secionais de RS, SP, MG, PA, PE, BA, pelo Instituto dos Advogados Brasileiros, pelo Instituto dos Advogados do Rio Grande do Sul, pela Faculdade de Direito da USP, e pela Federação do Comércio - SP (BROSSARD, 1977).
} 


\section{A mobilização do Ministério Público para a mudança institucional: do lobby às redes das mobilizações pró- democracia}

O projeto de reforma do Judiciário previa novas atribuições apenas ao PGR sem qualquer menção aos Ministérios Públicos estaduais. A levou emendas para a uniformização nacional da organização e da carreira à Comissão Mista, através do deputado Nelson Marchezan, que foram mantidas na Emenda Constitucional no 7 com a inclusão do artigo 96 prevendo lei complementar, de iniciativa do Presidente da República, que viria a estabelecer normas gerais a serem adotadas na organização do MP estadual.

A mobilização no Congresso Nacional, a partir do início do processo da reforma, foi acompanhada pelo engajamento de promotores e procuradores de justiça em grupos de estudos jurídicos e congressos nacionais, promovidos e patrocinados anualmente pelas associações de classe. Os grupos surgiram em São Paulo, no início dos anos 1970, como fórum de produção, discussão e disseminação de projetos, e se proliferaram nacionalmente, a partir da segunda metade da década. Os congressos anuais se converteram em outro canal de mobilização política. Como espaço interno de produção doutrinária e de negociação da pauta do movimento, os encontros passaram a municiar jurídica e politicamente as atividades associativas de lobby e de campanhas junto à opiniáo pública ${ }^{16}$.

O III Congresso Nacional do Ministério Público, em 1974, abriu o debate sobre a questão da independência em relação ao Poder Executivo, com base no Código de Processo Civil (CPC) de $1973^{17}$, que havia previsto a intervenção do MP em causas envolvendo o interesse público ${ }^{18}$. Se a intenção inicial era estender a

\footnotetext{
16 "Foi o tempo em que se multiplicavam os congressos do Ministério Público em todo o país, estimulados pela Confederação Nacional como estratégia para promover o Ministério Público junto aos governos, à opinião pública e junto aos políticos em geral. Era uma arma política. Não só estudávamos as leis, os projetos de código, mas, sobretudo, usávamos essa arma política em todo o país como forma de influenciar até os governantes" (sic) (FREITAS, 2003, p. 7).

${ }^{17}$ A primeira redação do anteprojeto do Código, realizada pelo promotor de justiça do Rio Grande do Sul, Sérgio da Costa Franco, havia previsto a intervenção do MP como fiscal da lei nos processos que houvesse "interesse de pessoas jurídicas de direito público" (LOPES, 1976; MACHADO, 1985; ARANTES, 2002). As novas atribuiçóes funcionais tinham como alvo o controle da administração pública através da fiscalização nos casos de corrupção, um dos temas que se tornaram centrais da agenda política do regime militar (MINISTÉRIO PÚBLICO DE SÃO PAULO, 1971, p. 33).

${ }^{18}$ Conforme o Artigo 82, Lei no 5869 - Código de Processo Civil): “Compete ao Ministério Público intervir: I - Nas causas em que há interesses de incapazes; II - Nas causas concernentes ao estado da pessoa, pátrio poder, tutela, curatela, interdição, casamento, declaração de ausência e disposição de
} 
atuação do MP como advogado dos interesses estatais, a previsão genérica das causas públicas evidenciadas pela "natureza da lide ou qualidade da parte", ampliava a margem de interpretação jurídica quanto à natureza "pública" das modalidades de interesses, atores e conflitos a serem protegidos. A produção doutrinária convergia para a definição do "interesse público" como uma categoria redutível aos interesses individuais indisponíveis ou estatais enquanto aparato burocrático-administrativo. Dessa forma, no entendimento das lideranças reformistas, o CPC havia alçado a instituição à condição de representante da lei e não mais agente do Executivo ou da administração em geral (FERRAZ, 1997a, p. 38 e 39).

A tese da ampliação da atuação institucional em defesa de interesses sociais passou a ser sustentada pelos grupos de estudos que, em São Paulo, intensificaram as atividades em torno de temas de tônica social como acidentes de trabalho e riscos à saúde de trabalhadores, zoneamento e loteamento do solo, relaçôes de consumo e poluição industrial. No V Congresso Nacional do Ministério Público, em 1976, lideranças paulistas defendiam a adoção de nova estratégia política: a de buscar apoio não apenas junto às elites políticas, mas construir vínculos mais consistentes com a sociedade que passa a ser vista como fonte potencial de legitimidade das aspirações de independência institucional (FERRAZ, 1997).

\section{Em busca de unidade nacional: a mobilização para a Lei Orgânica Nacional (1974-1981)}

Embora o regime militar tenha mantido o controle do sistema político através das eleições presidenciais, a abertura controlada foi "atropelada pelo processo de democratização da sociedade” (SALLUM, 1996, p. 42). As possibilidades de mobilização pública foram ampliadas, em 1978, com a revogação do AI-5 e a redução da censura prévia nos meios de comunicação. No ano seguinte, a anistia e a extinção do bipartidarismo propiciaram a diversificação de lideranças e a partidarização de movimentos sociais antes albergados ou simpáticos ao MDB (KINZO, 1988; SALLUM, 1996). A liberalização política culminou na sequência de vitórias do MDB nas eleiçóes para o legislativo, para Executivos locais e para governos de estado, em 1974, 1978 e 1982. Esse êxito constituiu um efeito demonstração para mobilizaçôes de vários setores da sociedade civil - movimento sindical, organizaçôes de classe média, profissionais liberais, funcionários públicos e moradores da periferia dos 
centros urbanos - constituindo um ciclo de protestos, no período de 1977 a 1984 (BOSCHI, 1987).

Da onda de manifestações públicas emergiram novas modalidades de conflito social, de caráter difuso, sem expressão jurídica no sistema político, como a proteção ambiental e as relaçôes de consumo. A dinâmica do processo político em torno das questôes ambientais, em particular, favoreceu o ativismo precoce do MP no campo dos interesses sociais. A atribuição dos problemas ambientais ao modelo de desenvolvimento econômico e à centralização do processo decisório politizou o protesto ambientalista, conectando-o ao movimento pela redemocratizaçáo (ALONSO, COSTA e MACIEL, 2007) ${ }^{19}$. A área ambiental já contava com uma burocracia nacional especializada, a Secretaria Especial do Meio Ambiente (SEMA), criada em 1973 em resposta às pressóes internacionais via Conferência de Estocolmo. Em 1974, o II Plano Nacional de Desenvolvimento (PND) do Governo Geisel já previa o controle da poluição industrial como uma das diretrizes das políticas urbanas a serem implementadas nos níveis nacional e estadual. Do lado do governo, estava à frente da SEMA Paulo Nogueira Neto, professor de História Natural da USP, advogado e ativista ligado a Fundação Brasileira de Conservação do Ambiente Natural (FBCN). Do lado do MP estava o promotor de justiça, Paulo Affonso Leme Machado, um dos raros juristas especializados em matéria ambiental naquele momento, conectado com a rede ambientalista nacional e internacional ${ }^{20}$.

As pressões sociais para a mudança do aparato legal-estatal se intensificaram na segunda metade dos anos de 1970. A circulação de Paulo Affonso Leme Machado entre o cargo de promotor, o ativismo civil e a assessoria à SEMA o transformaram no primeiro brocker entre o movimento institucional, as mobilizaçôes pró-democracia e a burocracia estatal ${ }^{21}$. Com a intensificação dos protestos sociais, a SEMA iniciou a

\footnotetext{
${ }^{19}$ Mobilizaçóes nacionais como a Campanha em Defesa da Amazônia (1978), Campanha contra a Utilização de Energia Nuclear (1980), e Adeus Sete Quedas (1982) envolveram, além de grupos ambientalistas, movimento estudantil, movimentos sociais populares, movimentos culturais, comunidade científica, políticos do $\mathrm{MDB}$, artistas, associaçóes profissionais de classes médias, OAB e setores progressistas da Igreja Católica (ALONSO, COSTA e MACIEL, 2007).

${ }^{20}$ O promotor Paulo Affonso Leme Machado havia realizado, no início dos anos de 1970, mestrado em direito ambiental na Universidade de Estrasburgo, na França, e, ao chegar ao Brasil, fundou a Sociedade Brasileira de Direito do Meio Ambiente, em 1979.

${ }^{21}$ O I Simpósio Nacional de Ecologia, realizado em setembro de 1978, em Curitiba, aprovou a tese "A proteção penal do meio ambiente", levada pelo advogado Ariel Dotti que, em seguida, a encaminhou à Comissão de Juristas, da qual era membro. A Comissão havia sido criada pelo Ministro da Justiça, Petrônio Portela, em 1979, para propor reformas no campo penal (DOTTI, 1995). Em março de 1980, o Grupo de Estudos Campos Salles levou ao Ministro da Justiça, Ibrahim Abi-Ackel a tese "O
} 
elaboração do anteprojeto de lei destinado a definir diretrizes para a política ambiental nacional. Paulo Nogueira Neto entregou a Paulo Affonso Leme Machado a revisão do anteprojeto ${ }^{22}$.

$\mathrm{Na}$ sua versão final, a Lei da Política Nacional do Meio Ambiente (Lei ${ }^{\circ}$ 6.938), promulgada em agosto de 1981, criou mecanismos participativos nas políticas públicas, como o Conselho Nacional do Meio Ambiente (CONAMA), e previu a legitimidade do MP para propor ação de responsabilidade civil e judicial destinada a impedir ou fazer cessar a atividade poluidora ou danosa ao meio ambiente ${ }^{23}$. Três meses mais tarde, foi aprovada a Lei Complementar no 40 - a Lei Orgânica Nacional, que estabeleceu parâmetros para a instituição e para a carreira: uniformizou as competências, garantias e prerrogativas da instituição nos estados, definiu o MP como instituição voltada para a defesa de interesses sociais indisponíveis e estabeleceu a escolha do PGE entre os membros da carreira do MP (VASCONCELOS, 1985). A lei implementava a emenda ao art. 96 da Constituição. Por resultar de pressão do movimento associativo, durante reforma do Judiciário, teve significado inverso da Lei Orgânica da Magistratura, aprovada em 1979, que foi combatida pelos juízes como instrumento de centralização e disciplina patrocinado pelo regime ${ }^{24}$.

Ministério Público e a Tutela Penal do Meio Ambiente”, aprovada no VII Seminário Jurídico dos Grupos de Estudos, realizada em 1979.

22 Enquanto isso, a Associação Paulista do Ministério Público iniciou campanha nacional de divulgação da profissão do promotor de justiça como "defensor" e não apenas como "acusador" no processo judicial. Em 1979, programas semanais na Rádio Cultura, tal como "Promotor Público acusação ou defesa", foram realizados com o objetivo de "apresentar a estrutura do Ministério Público, a natureza da atuação nas diversas áreas da sociedade e ressaltar os aspectos de proteção e segurança decorrentes da sua atuação" (APMP, 1979, p. 1).

${ }^{23}$ Segundo relatou o promotor Paulo Affonso Leme Machado, em entrevista, não havia qualquer possibilidade política para propor naquele momento a participação de organizaçóes da sociedade civil na proposição de açóes judiciais, como havia deixado claro Paulo Nogueira Neto ao lhe entregar o anteprojeto para revisão. A Lei da Política Nacional do Meio Ambiente foi recebida pela comunidade científica e por ativistas, na $34^{\mathrm{a}}$ reunião da SBPC, em 1982, como um caminho aberto para fazer chegar medidas de proteção ambiental ao Judiciário.

${ }^{24}$ Os vetos do Executivo recaíram nos pontos do projeto que propunham a garantia de independência e autonomia institucional: 'Não digo que se pudesse fazer muita coisa nesses tempos do regime militar, porque, é claro, que não ia se falar muito em independência para um regime ditatorial [...] mas a questão era formar opinião" (sic) (FREITAS, 2003, p. 7). 


\section{Em busca de novos instrumentos judiciais: a mobilização em torno da Ação Civil Pública (1983-1985)}

O processo político, a partir de 1982, abriu novos espaços de engajamento com a vitória eleitoral de governadores de oposição. Em São Paulo, Franco Montoro do PMDB implantou conselhos participativos cujos estatutos previam a representação da PGE junto a outras instituições, organizações e movimentos sociais. Novos órgãos na área dos interesses difusos foram criados, como a Secretaria do Meio Ambiente e a Secretaria do Consumidor para a qual foi convidado para secretário o entáo, Procurador Geral da Justiça do Ministério Público de São Paulo, Paulo Frontini. Embora a Secretaria não tenha vingado, a iniciativa de Montoro evidenciava a clara intenção de franquear a presença da instituição no processo de reformas do aparelho estatal. A inserção de membros do MP em órgãos colegiados da política ambiental permitia a formação de alianças com a oposição partidária e lideranças ambientalistas, bem como a socialização nos meandros técnicos e políticos do novo campo de ação profissional.

Com avanço da democratização, a imprensa passou a ter papel crucial na veiculação nacional de acidentes e danos ambientais, dos protestos ambientalistas e das medidas judiciais propostas pelo MP. Inovações organizacionais foram sendo implementadas, a partir de 1983, como as curadorias especializadas, que se converteram em espaço de atuação extrajudicial onde se estreitavam vínculos da instituição com ativistas e grupos ${ }^{25}$.

A inexistência de um sistema de proteção legal dos interesses difusos limitava as modalidades de interesses sociais a serem tutelados e, ainda, deixava em aberto a definição da natureza interveniente ou agente da legitimidade do MP no processo judicial. O grupo de juristas que formulava o anteprojeto de Lei da Ação Civil Pública alegava duas razóes contra a legitimidade do MP na matéria. Primeiro, sua vinculação ao Executivo constituiria fator potencialmente inibidor da sua ação institucional contra os organismos públicos, os mais frequentes responsáveis pelas lesôes. Segundo, dada a relevância dos aspectos extrajurídicos (técnico-científicos, sociais e econômicos) implicados nos conflitos de natureza difusa, o MP era considerado inadequado para atuar nos processos judiciais (GRINOVER, 1984). O deputado Flávio Bierrembach acolheu a sugestão no projeto apresentado ao

\footnotetext{
${ }^{25}$ No período, Edis Milaré era coordenador da Curadoria do Meio Ambiente de São Paulo. Durante a crise de Cubatão, propôs medidas judiciais em conjunto com o grupo ambientalista OIKOS (MAC DOWELL DOS SANTOS, 1990). Tornou-se membro do conselho consultivo da SOS Mata Atlântica, em 1986. Ambos os grupos, fundados e liderados pelo advogado e ativista Fábio Feldman, eram influentes na rede ambientalista nacional (ALONSO, COSTA e MACIEL, 2007).
} 
Congresso Nacional, em 1983, no qual as associaçóes civis eram os principais agentes legitimados para a proposição das açóes coletivas.

Os membros do MP reagiram com intenso ativismo doutrinário, substituindo o conceito "ação coletiva" pelo de "ação civil pública" para legitimar a atuação em analogia ao papel institucional no processo penal (ARANTES, 2002). Nesse momento não se tratava mais de ressaltar a modalidade pública dos interesses protegidos, como ocorrera na discussão sobre a noção de interesse público, mas de fundamentar a legitimidade do MP como sujeito da ação. Para promotores e procuradores de justiça, a performance nas açóes judiciais propostas com base na Lei da Política Nacional do Meio Ambiente sinalizaria a disposição institucional de atuar em defesa dos interesses sociais ${ }^{26}$ (FERRAZ, 1997a).

A CONAMP apresentou novo anteprojeto de lei, elaborado pelo MP paulista, ao Executivo Federal. A proposta ampliava o alcance da lei para abranger a tutela do consumidor e de outros "interesses difusos" e regulava a instauração e o arquivamento do inquérito civil (MAZZILLI, 2002, p. 310). O anteprojeto foi acolhido pelo Ministério da Justiça e encaminhado ao Congresso. Como projeto de iniciativa do Executivo, teve tramitação mais rápida que o anteprojeto original dos juristas e assim foi a base da Lei da Ação Civil Pública (Lei 7.347/85)27.

O período entre a apresentação do anteprojeto do MP e a promulgação da lei foi marcado por manifestaçôes públicas de crítica do grupo de juristas e advogados ao então chamado "projeto do Ministério Público de São Paulo" (FIORILLO, 1999), mas condições políticas favoreciam o projeto de afirmação institucional.

Primeiro, o MP tinha caminho livre para postular legitimidade ativa para agir, dada a inexistência de instituiçôes talhadas para abrigar os novos interesses sociais. Ademais, a adoção de novos arranjos institucionais, como o aventado modelo escandinavo do ombudsman, trazia riscos e incertezas. O grupo de juristas responsável pelo projeto original, cauteloso, não propôs explicitamente a criação de novos organismos públicos, e sim optou por dar forma jurídica aos novos interesses, garantir

\footnotetext{
26 “O Ministério Público está [...] bastante inclinado a agir nessa área [...] Um único órgão do Ministério Público de São Paulo (o Central de Avaliaçóes do Exército - CAEX) ajuizou, na Capital, no ano de 1982, 244 pedidos de interdição e 312 ações civis públicas; em 1983, o mesmo órgão propôs 468 açóes civis, das quais 224 eram pedidos de interdição” (FERRAZ, 1997a, p. 20).

${ }^{27}$ A norma de extensão da Lei da Ação Civil Pública a todos os interesses difusos foi vetada pelo Presidente da República, alegando risco de insegurança jurídica. Com o art. 110 do Código de Defesa do Consumidor de 1990 (Lei n. 8078/90), a norma foi introduzida na Lei 7.347/85 (FERRAZ, 1997b, p.10).
} 
a legitimidade das associações civis e mobilizar com limitações a estrutura institucional já existente do MP (FIORILLO, 1999).

Segundo, naquela altura do processo político, a inserção do MP já lhe permitia angariar outros apoios para as disputas no interior da comunidade jurídica em torno da institucionalização da proteção legal aos interesses difusos. Segmentos sociais organizados, como a comunidade científica e associaçóes ambientalistas, apoiaram a preparação do projeto de lei no Executivo, promovendo campanha junto ao presidente Sarney para aprovação do anteprojeto do MP (APMP, 1985).

Por fim, a mobilização dos membros do MP encontrou ampla guarida no próprio governo. A agenda de reformas do governo Sarney estava comprometida não apenas com o esvaziamento do caráter autoritário da legalidade vigente, mas com a construção de nova institucionalidade, permeável aos interesses e direitos sociais (SALLUM, 1996).

A titularidade da ação civil pública representou para o movimento institucional retaguarda legal e meio político para atrelar as novas atribuições ao tema $\mathrm{da}$ independência institucional. Afinal, o embate com os juristas havia evidenciado que a desvinculação constitucional com o Executivo se tornara, a partir de agora, imperativa para a legitimação política da nova agenda de atuação.

\section{Considerações finais}

O processo de mudança institucional do Ministério Público é parte da dinâmica mais ampla da transição política brasileira. $O$ regime militar não só bloqueou as demandas dos Ministérios Públicos estaduais de autonomia institucional e funcional como as contrariou, eliminando a autonomia precária do PGR e sobrepondo um modelo de subordinação ao Poder Executivo. O projeto centralizador da reforma do Judiciário de 1974-77 acabou promovendo a aproximação dos juristas com a mobilização pró-democracia em dois sentidos. Por um lado, favoreceu alianças entre os movimentos associativos das carreiras jurídicas, a oposição política do MDB e grupos da sociedade civil a favor da redemocratização e do estado de direito. Por outro lado, contribuiu para que as demandas corporativas e institucionais fossem incorporadas à pauta dos movimentos ligados aos protestos anti regime. Nesse sentido, a volta ao estado de direito passou a significar também o fortalecimento e o insulamento das instituiçóes judiciais.

As estratégias e alianças adotadas pelo movimento associativo do MP, a partir de 1974, foram relevantes para a conquista da independência institucional e do novo papel na Constituição de 1988. Em primeiro lugar, a construção doutrinária da noção de interesse público, acompanhada do engajamento nas mobilizações 
ambientalistas, foi transformando o MP numa alternativa institucional viável e disponível, naquele momento, para canalizar os novos problemas e conflitos sociais. Em segundo lugar, a interação com as redes pró-democracia contribuiu para ampliar o padrão tradicional de alianças, bem como as estratégias de mobilização para além do lobby. Nesse processo, o MP atraiu para si visibilidade pública inédita que se converteu no apoio político de grupos, movimentos sociais, comunidade científica e meios de comunicação ao perfil potencialmente politizado de atuação profissional. Durante a Constituinte, a rede ambientalista nacional, liderada por Fábio Feldman, estava engajada no lobby em favor do MP no Parlamento, bem como em inúmeras manifestações de apoio via mídia (MAZZILLI, 1996).

As novas credenciais públicas adquiridas pelo MP coadunavam com os dois temas de forte apelo político e simbólico que animaram os debates na Constituinte (MARTÍNEZ-LARA, 1996). O tema da construção de instituições judiciais permeáveis à institucionalização das novas modalidades de conflito social e, portanto, dispostas a renovar o ethos burocrático tradicional das identidades profissionais jurídicas, e o tema da criação de mecanismos e instituiçóes autônomas que permitissem ampliar os canais de representação de interesses e, assim, reverter a tradição de hipertrofia e de insulamento do Executivo frente aos demais agentes e interesses sociais e políticos.

Uma hipótese razoável, portanto, é a de que o capital social, político e simbólico acumulado permitiu ao MP enfrentar com sucesso, na Constituinte, oponentes no interior da comunidade jurídica e política, e angariar decisóes políticas favoráveis à realização da sua pauta. Nesse sentido, o movimento institucional foi bem sucedido, não pelo uso exclusivo do lobby, mas porque foi ganhando organicidade e legitimidade na medida em que se associava às outras mobilizações políticas cujo volume e ritmo, como sabemos, foram decisivos para acelerar o processo da transição política.

A trajetória do movimento político de promotores e procuradores de justiça parece mostrar que a tão notável singularidade do perfil institucional do Ministério Público brasileiro, frente aos congêneres internacionais, é expressão da própria singularidade da experiência da sociedade brasileira ao longo da democratização. 
Débora Alves Maciel é Professora do Departamento de Ciências Sociais da Escola de Filosofia, Letras e Ciências Humanas da Universidade Federal de São Paulo - EFLCH/UNIFESP, Membro do Grupo de Grupo de Pesquisas em Direito e Politica do CEIPOC/IFCH/Unicamp e Pesquisadora do Cebrap. E-mail: deboraalvesmaciel@gmail.com.

Andrei Koerner é Professor do Departamento de Ciência Política IFCH/Unicamp, Coordenador do Grupo de Pesquisas em Direito e Politica do CEIPOC/IFCH/Unicamp, Pesquisador do Cedec e do INCT/Ineu. E-mail: andreik@uol.com.br.

\section{Referências}

ALONSO, Ângela; COSTA, Valeriano; MACIEL, Débora. Identidade e estratégia na formação do movimento ambientalista brasileiro. Revista Novos Estudos Cebrap, São Paulo, n. 79, p. 151-167, nov. 2007.

ALVES, Maria Helena M. Estado e oposição no Brasil (1964-84). Petrópolis: Vozes, 1985, p. 56 e 61.

APMP. Informativo Semanal. Associação Paulista do Ministério Público, São Paulo, n. 154, mar. 1979.

. Informativo Semanal. Associação Paulista do Ministério Público, São Paulo, v. 10, n. 253, 30 nov. 1985.

ARANTES, Rogério Bastos. Ministério Público e Politica no Brasil. São Paulo: Editora Sumaré, 2002.

BOSCHI, Renato R. A Arte da Associação: política de base e democracia no Brasil. Rio de Janeiro: Iuperj, 1987.

BROSSARD, Paulo. É Hora de Mudar. Porto Alegre: L\&PM, 1977.

DOTTI, Rene Ariel. A proteção do meio ambiente - dados para uma visão histórica. In: MILARÉ, Edis (Coord.). Ação civil pública - Lei 7.347/85: reminiscências e reflexóes após dez anos de aplicação. São Paulo: Revista dos Tribunais, 1995, p. 406-437.

ENGELMAN, Fabiano. Sociologia do campo jurídico: juristas e usos do direito. Porto Alegre: Sérgio Antônio Fabris, 2006.

FALCÃO NETO, Joaquim. Cultura jurídica e democracia: a favor da democratização do Judiciário. In: LAMOUNIER, Bolivar et al. (Org.). Direito, cidadania e participação. São Paulo: T. A. Queiroz, 1981, p. 3-20.

FERRAZ, Antonio A. Mello de Camargo. Ministério Público: quando o passado aponta o futuro. Revista da Associação Paulista do Ministério Público (APMP), São Paulo, v. 1, n. 5, p. 35-39, abr. 1997 a. 
- Primórdios da ação civil pública. In: Seminário 15 anos de ação civil pública - Folêmicas e controvérsias - Evolução legislativa e tendências jurisprudenciais, São Paulo, Ministério Público Federal, 13 jun. 2000.

FIORILlO, Celso Antonio Pacheco. Associação civil e interesses difusos no direito processual civil brasileiro. 1999. Dissertação (Mestrado em Direito Processual Civil) - Programa de PósGraduação em Direito, Pontifícia Universidade Católica, São Paulo, 1999.

FREITAS, Oscar Xavier de. 2003. Depoimento concedido ao Memorial do Ministério Público do RS. Ministério Público de Rio Grande do Sul, São Paulo, 02 jul. 2003. Disponível em:

<http://www.mprs.mp.br/areas/memorial/anexos_noticias/entrevista_oscar_xavier_de_freitas.pdf >. Acesso em: 02 abr. 2014.

GRINOVER, Ada. A tutela dos interesses difusos. São Paulo: Max Limonad, 1984.

KERCHE, Fábio. O Ministério Público e a constituinte de 1987/88. In: SADEK, Maria Tereza (Org). O sistema de justiça. Rio de Janeiro: Centro Edelstein de Pesquisas Sociais, 2010, p. 106-137.

KINZO, Maria D. Oposição e autoritarismo. Gênese e trajetória do MDB, 1966-79. São Paulo: Idesp/Vértice, 1988.

KLEIN, Lucia; FIGUEIREDO, Marcus F. Legitimidade e coação no Brasil pós-64. Rio de Janeiro: Forense-Universitária, 1978.

KOERNER, Andrei. A reforma Judiciária no governo Geisel. Seminário de História do Direito e das Instituiçóes Políticas, Rio de Janeiro, FCRB/IESP-UERJ, 10 e 11 out. 2012.

KOERNER, Andrei; FREITAS, Lígia Barros. O Supremo na Constituinte e a Constituinte no Supremo. Lua Nova, São Paulo, n. 88, p. 141-184, 2013.

LOPES, José Fernando da Silva. O Ministério Público e processo civil: as posiçóes fundamentais do Ministério Público no novo processo civil brasileiro. São Paulo: Saraiva, 1976.

MAC DOWELL DOS SANTOS, Maria Cecilia. A gestão jurídico-politica dos conflitos ecológicos: um estudo sobre as reformas de proteção judicial do meio ambiente em Cubatão (19811987). Dissertação (Mestrado em Direito) - Departamento de Filosofia e Teoria Geral do Estado, Universidade de São Paulo, São Paulo, 1990.

MACEDO JR., Ronaldo Porto. A evolução institucional do Ministério Público. In: FERRAZ, Antonio A. Mello de Camargo (Coord.). Ministério Público: instituição e processo. São Paulo: Atlas, 1997, p. 36-65.

MACHADO, Joaquim Maria. O Ministério Público na Justiça Civil (casos de intervenção obrigatória) - O interesse público evidenciado. Justitia, São Paulo, v. 47, n. 131, p. 352-363, set. 1985.

MARTÍNEZ-LARA, Javier. Building Democracy in Brazil: The Politics of Constitutional Change 1985-1995. New York: St. Martin's Press, 1996.

MAZZILLI, Hugo Nigro. Regime jurídico do Ministério Público. São Paulo: Ed. Revista dos Tribunais, 1996.

Independência do Ministério Público. In: FERRAZ, Antonio A. Mello de Camargo (Coord.). Ministério Público: instituição e processo. São Paulo: Atlas, 1997.

- Depoimento concedido ao Memorial do Ministério Público do RS. Ministério Público de

Rio Grande do Sul, São Paulo, 12 jun. 2002. Disponível em: 
<http://www.mprs.mp.br/areas/memorial/anexos_noticias/entrevista_hugo_nigro_mazzilli.pdf >. Acesso em: 02 abr. 2014.

MINISTÉRIO PÚBLICO DE SÃO PAULO. Anais do I Congresso Nacional do Ministério Público, São Paulo, dez. 1971.

ROCHA, Antonio Sérgio. Genealogia da Constituinte. Do autoritarismo à democratização. Lua Nova, São Paulo, n. 88, p. 29-87, 2013.

SALLES, Carlos Alberto de. Entre a Razão e a Utopia: A Formação Histórica do Ministério Público. In: MACEDO JR., Ronaldo Porto; VIGLIAR, José Macedo Menezes (org). Ministério Público Il: Democracia. São Paulo: Atlas, 1999, p. 13-43.

SALLUM, Brasílio Jr. Labirintos: dos generais a nova república. São Paulo: Hucitec, 1996.

SKIDMORE, Thomas. Brasil: de Castelo a Tancredo. Rio de Janeiro: Paz e Terra, 1988.

VASCONCELOS, Fernando A. A posição do Ministério Público na Constituição. Justitia, São Paulo, v. 47, n. 131, p. 157-168, set. 1985.

Texto recebido em 02 de setembro de 2014. Aprovado em 29 de setembro de 2014. 
